\title{
Experimental research on drying control condition with minimal effect on concrete strength ${ }^{1}$
}

\author{
Guohui Zhang ${ }^{\mathrm{a}}$, Zongli Li ${ }^{\mathrm{a}, *}$, Linfei Zhang ${ }^{\mathrm{b}}$, Yujuan Shang ${ }^{\mathrm{a}}$, Hang Wang ${ }^{\mathrm{a}}$ \\ ${ }^{\mathrm{a}}$ College of Water Resources and Architectural Engineering, Northwest A\&F University, Yangling 712100, PR China \\ ${ }^{\mathrm{b}}$ College of Mechanics and Materials, Hohai University, Nanjin 210098, PR China
}

\section{A B S T R A C T}

In order to obtain the drying control condition with no or minimal effect on concrete strength, various drying temperatures conditions are used as $150{ }^{\circ} \mathrm{C}, 120{ }^{\circ} \mathrm{C}, 105{ }^{\circ} \mathrm{C}, 85{ }^{\circ} \mathrm{C}$ and $60{ }^{\circ} \mathrm{C}$, and the drying procedure of continuous and intermittent cyclic are presented independently in this study. The change of specimen mass is recorded in the drying process, and the compressive strength and splitting tensile strength are measured after the natural cooling. The results show that the concrete compressive strength initially decreases and then increases with the increase in drying temperature, while the splitting tensile strength always decreases., The relative compressive and splitting tensile strength of concrete in dry state are 1 and 0.99 respectively after $115.5 \mathrm{~h}$ of continuous drying at $105{ }^{\circ} \mathrm{C}$, which denotes the optimal drying control condition has minimal effect on the strength, and efficiency is suitable. Finally, the change in components and defects structure of the concrete after minimal damage drying is analyzed through the thermo-gravimetric analysis, electron microscope scanning and industrial CT scanning.

Keywords: Concrete; Drying characteristic; Compressive strength; Splitting tensile strength; Components and defects

\section{Introduction}

The amount of pore water in concrete has a significant influence on its durability [1-6]. In order to understand the influence laws of moisture content on mechanical properties of the concrete, a drying treatment for concrete

\footnotetext{
* Corresponding author.

E-mail addresses: bene@ nwsuaf.edu.cn (Z. Li).
} 
specimens is required to obtain the moisture content of the concrete specimens. The ideal drying treatment on the effect of eliminating physical water in the concrete should be obtained under the condition of inducing no or minimal changes in the concrete strength. However, there are no provisions on control of drying temperature and other conditions in current codes and standards, which cause researchers to use different types of drying conditions. Specimens need to be dried first for studying the differences in mechanical properties of dry and saturated concrete. For this, Wang et al. [7] placed the concrete specimens in indoor conditions for presetting and to obtain the dry state. For obtaining the dry state, Wang and $\mathrm{Li}[8]$ dried the concrete for 2 days at $30{ }^{\circ} \mathrm{C}$ and $50{ }^{\circ} \mathrm{C}$, respectively, and then at $65{ }^{\circ} \mathrm{C}$ for 6 days. In another experiment, Wang and Li [9] dried the concrete for 1 day at $50{ }^{\circ} \mathrm{C}$, afterwards the temperature is gradually increased from $65{ }^{\circ} \mathrm{C}$ to $75{ }^{\circ} \mathrm{C}$, with drying of concrete at each temperature for 3 days. Finally, it is dried at $85{ }^{\circ} \mathrm{C}$ until the change in mass becomes constant. For studying the effect of laws of moisture content on mechanical properties of concrete, researchers generally dry the concrete completely at initial stage and then immersed it for different periods to obtain the concrete with various moisture contents. Liu et al. [10] placed the concrete specimens in the oven for drying at $45{ }^{\circ} \mathrm{C}$ until the change in mass becomes constant. In case of Zhou et al. [11,12], the dry state has been reached after drying the concrete specimens at $105{ }^{\circ} \mathrm{C}$,i.e., at this temperature the mass becomes unchanged. Although the drying procedures of concrete are mostly the same, the different drying conditions cause variable loss in water, the required drying time and drying states are all vary. Since the drying process corresponds to the escape of water from the concrete, a rapid escape of water cause serious damages such as initiation, convergence and propagation of micro-cracks in the concrete [13-15]. Coarse and fine aggregates as well as cement binding materials in concrete of heterogeneous nature exhibit different thermal performances, therefore the physical and chemical reactions between these materials are complicated [16,17]. This makes significant differences in appearance, strength and phase compositions of concrete under different drying conditions. Those differences will certainly affect the correct evaluation of the changes that occurred in the mechanical 
properties of the concrete with different moisture contents.

In this paper, process of water loss and drying results are investigated for the concrete under different drying conditions by using the different drying temperatures and mechanisms. The influence laws of different drying conditions on concrete compressive and splitting tensile strength are analyzed for providing a suitable drying process with having very low or no damage on concrete strength and high drying efficiency. This will provide the basis for experimental designs for the mechanical properties of concrete in the wet states.

\section{Experimental}

\subsection{Test materials and equipment}

In this investigation, a complex Portland Cement (P.C32.5) produced in the Jidong cement plant of China was used in all formulations. The water was obtained directly from the city drinking water supply. The aggregate included medium sand (fine aggregate) and pebbles (coarse aggregate) produced in the Weihe plant of Yangling in Shaanxi Province, and the fineness modulus, clay content, apparent density and bulk density of the sand were 2.4, $0.8 \%, 2590 \mathrm{~kg} / \mathrm{m}^{3}$, and $1540 \mathrm{~kg} / \mathrm{m}^{3}$ respectively, while the clay content, apparent density, bulk density and maximum aggregate size of the pebbles were $0.6 \%, 2650 \mathrm{~kg} / \mathrm{m}^{3}, 1563 \mathrm{~kg} / \mathrm{m}^{3}$, and $40 \mathrm{~mm}$, respectively. The strength level of concrete in this research was $\mathrm{C} 20$, which was cured under the standard conditions $\left(20^{\circ} \mathrm{C} \pm 2{ }^{\circ} \mathrm{C}\right.$, $\mathrm{RH}>95 \%$ ) for 28 days. Concrete specimens were standard cube specimens whose length of side was $150 \mathrm{~mm}$, and the mix proportions of concrete used are shown in Table 1 according to Chinese national standard DLT5330-2015 (the Code for Mix Design of Hydraulic Concrete). Drying equipment was electro- thermostatic blast oven whose temperature uniformity was within $\pm 2.5 \%$, and the volatility was within $1{ }^{\circ} \mathrm{C}$. The operating temperature range was room temperature from $300{ }^{\circ} \mathrm{C}$. Both compressive strength and splitting tensile strength tests of concrete were carried out using a microcomputer controlled fully automatic pressure tester, which was manufactured by Shanghai Xinsasi Measuring Instrument \& Equipment Manufacturing Co., Ltd., China, whose model number was YAW4206 
and whose maximum test force was $2000 \mathrm{kN}$, and the concrete strength test was conducted according to the Chinese national standard SL352-2006 (Hydraulic Concrete Test Procedure) [18].

Table 1

Mix proportion and major parameters of concrete specimen.

\begin{tabular}{|c|c|c|c|c|c|c|c|c|}
\hline \multicolumn{5}{|c|}{ Mix proportion $\left(\mathrm{kg} \cdot \mathrm{m}^{-3}\right)$} & \multirow{2}{*}{$\begin{array}{l}\text { Water- } \\
\text { Cement } \\
\text { ratio }\end{array}$} & \multirow{2}{*}{$\begin{array}{l}\text { Sand ratio } \\
(\%)\end{array}$} & \multirow{2}{*}{$\begin{array}{l}\text { Slump } \\
(\mathrm{mm})\end{array}$} & \multirow{2}{*}{$\begin{array}{l}\text { Compressive } \\
\text { strength }(\mathrm{MPa})\end{array}$} \\
\hline Water & Cement & Sand & $\begin{array}{l}\text { Diminutive } \\
\text { stone }\end{array}$ & $\begin{array}{l}\text { Medium-sized } \\
\text { stone }\end{array}$ & & & & \\
\hline 150 & 273 & 615 & 685 & 685 & 0.55 & 30 & $30-50$ & 27 \\
\hline
\end{tabular}

\subsection{Experimental procedure}

The controlling factors in the experiment include the drying temperatures and the mechanisms. Drying temperature is realized by setting the operating temperature of the drying oven at $60{ }^{\circ} \mathrm{C}, 85{ }^{\circ} \mathrm{C}, 105{ }^{\circ} \mathrm{C}, 120{ }^{\circ} \mathrm{C}$ and $150{ }^{\circ} \mathrm{C}$. Drying mechanisms include the continuous drying and the intermittent drying cycle. Continuous drying means that the specimens will be dried continuously under preset drying conditions until its reach the drying state. Intermittent drying cycle involve the drying of specimens continuously for $4 \mathrm{~h}$ under the preset drying conditions, afterwards the heating and air-blowing functions in the drying oven are shut down and specimens are naturally cooled down to the room temperature, followed by another continuous drying for $4 \mathrm{~h}$. The specimens are exposed to such reversed drying cycle until they reach the drying state. Concrete cube specimens after 28 days of standard curing are divided into 11 groups according to the preset controlling factors, in which the 1st group is used as standard one, and the specimen strength of the 1st group is measured directly without implementing any drying temperature after 28 days of standard curing. The rest including the 2 nd to 11 th groups are shown in Table 2 . Among the six specimens in each group, three of them are used to measure compressive strength, while the other three specimens are kept separately to measure the splitting tensile strength. 
Table 2

The experiment group and the control group.

\begin{tabular}{|c|c|c|c|c|c|c|c|c|c|c|}
\hline Group No. & 2 & 3 & 4 & 5 & 6 & 7 & 8 & 9 & 10 & 11 \\
\hline Temperature $\left({ }^{\circ} \mathrm{C}\right)$ & 60 & 85 & 105 & 120 & 150 & 60 & 85 & 105 & 120 & 150 \\
\hline Mechanism & \multicolumn{7}{|c|}{ Continuous dry } & \multicolumn{3}{|c|}{ Intermittent drying } \\
\hline
\end{tabular}

Specimens are collected from the standard curing room and a wet cloth is used to wipe their surfaces to remove any water. Afterwards, specimens are weighed and the mass of each group of specimens before drying is recorded. For drying the specimens, oven is preheated to predefined temperature and then each group of specimens are placed in using a stainless steel screen plate having dimensions of $800 \mathrm{~mm} \times 800 \mathrm{~mm}$. One group of specimens is dried each time and the specimens are distributed on the screen plate uniformly with intervals of $85 \mathrm{~mm}$ to assure the homogenous heating of specimens. At the early drying stage when there is large loss of water in concrete specimens, the specimen mass is measured every $1 \mathrm{~h}$. The drying oven is carefully maintained at the predefined temperature during the measurement process and the specimens are put back in and out as quickly as possible to avoid any experimental error. Every mass measurement process is taking about 5 minutes. After wards, at the later drying stages, the interval between mass measurements is extended to every $4 \mathrm{~h} \mathrm{to} 8 \mathrm{~h}$ until the specimens reached the complete drying state. Then after natural cooling, tests are conducted for concrete compressive and splitting tensile strengths.

\section{Results of the strength test}

\subsection{Analysis of drying characteristics}

The moisture content mentioned in this paper refers to the ratio of moisture weight to the wet concrete weight. Drying rate is the vaporized moisture mass on unit surface of concrete specimens per unit time, and expressed in $\mathrm{g} /\left(\mathrm{h} \cdot \mathrm{m}^{2}\right)$. To ensure the reliability of the results, drying time and rate, water loss and moisture content are all calculated based on the average of the six specimens in a group. By recording the dynamic change process of the concrete specimen mass under different drying conditions, and the changing curves of the concrete moisture 
content under continuous and intermittent drying conditions are obtained, as shown in Fig. 1(a) and (b). If the drying state is defined by the drying rate of concrete specimen slower than $1 \mathrm{~g} /\left(\mathrm{h} \cdot \mathrm{m}^{2}\right)$, the required drying time, loss of water mass and corresponding moisture content for each concrete specimens under different drying conditions are summarized in Table 3.
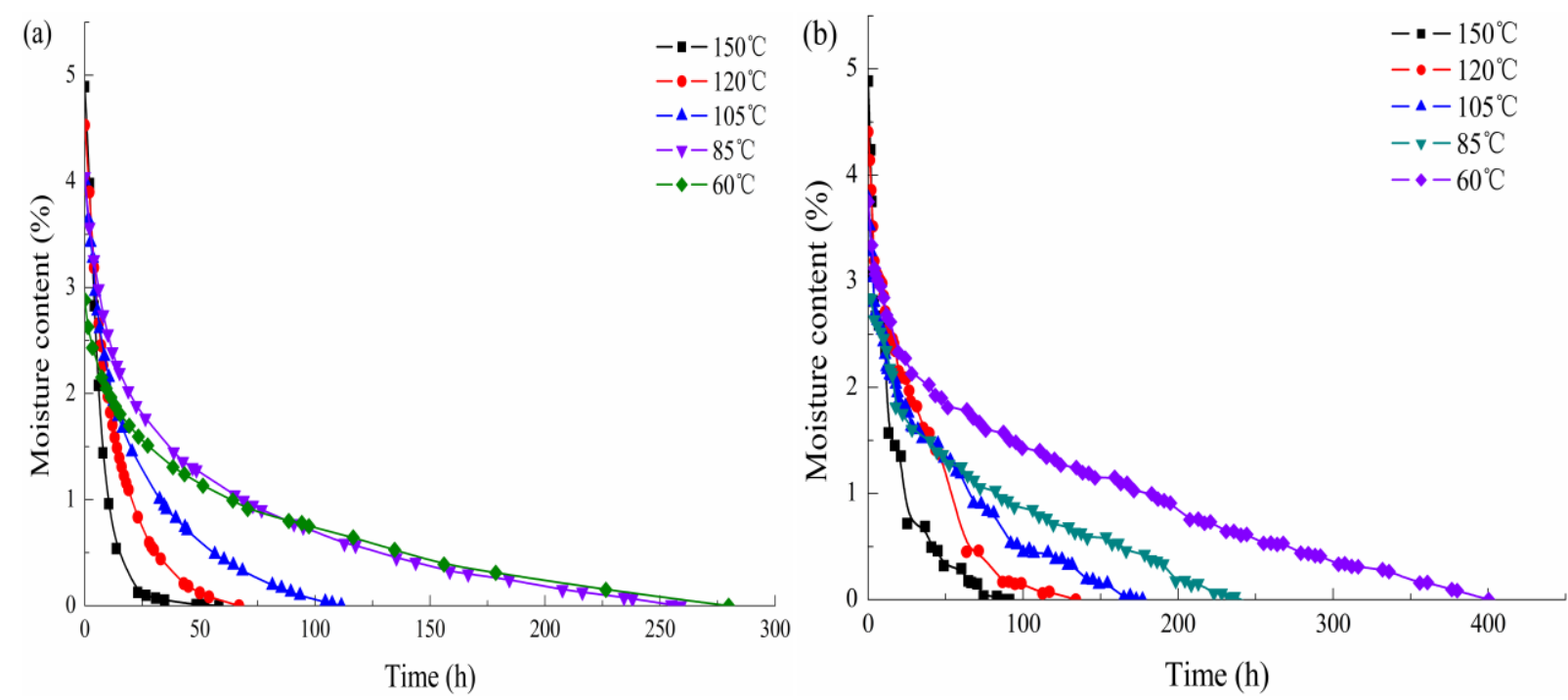

Fig. 1. Moisture content of concrete specimens under continuous drying (a) and intermittent drying conditions (b) (six replicates).

\section{Table 3}

Drying results of concrete specimens.

\begin{tabular}{llll}
\hline Group No. & Drying time $(\mathrm{h})$ & Lost moisture $(\mathrm{g})$ & Moisture content $(\%)$ \\
\hline 2 & 280 & 241 & 2.9 \\
3 & 256 & 332 & 4 \\
4 & 116 & 347 & 4.1 \\
5 & 67 & 378 & 4.5 \\
6 & 58 & 407 & 4.9 \\
7 & 469 & 235 & 2.8 \\
8 & 402 & 309 & 3.6 \\
9 & 177 & 311 & 3.8 \\
10 & 134 & 366 & 4.4 \\
11 & 91 & 407 & 4.9 \\
\hline
\end{tabular}

It is evident from the Fig. 1(a) and (b) that under continuous and intermittent drying cycle conditions, concrete moisture content decreases with the increase in drying time. At the early drying stage, the moisture content 
decreases quickly, and while with the increase in the drying time, the drying rate reduces at slower rate until it becomes constant. At this time, the specimen reaches the drying state. It can be seen from Table 3 that the required drying time, water loss and measured moisture content are different for the same concrete specimens under different drying conditions to reach the corresponding drying state. It is clear from the results that the higher drying temperature cause an increase in the drying rate, reduces the required drying time and increases the water loss. The required drying time, water loss and moisture content under continuous drying conditions (the sixth group) at $150^{\circ} \mathrm{C}$ are obtained as $0.2,1.7$ and 1.7, respectively, times more than that of the second group at $60{ }^{\circ} \mathrm{C}$. At the same temperature, in comparison to the intermittent drying cycle, the continuous drying causes a higher drying rate with less required drying time, and leads to the higher water loss and moisture content from the specimens. The required drying time, water loss and moisture content under continuous drying (the fifth group) at $120{ }^{\circ} \mathrm{C}$ are obtained as $0.5,1$ and 1 , respectively, times more than that of intermittent drying cycle at $120{ }^{\circ} \mathrm{C}$ (the tenth group).

\subsection{Effect of drying conditions on concrete strength}

As stipulated in the Chinese national standard SL352-2006 (Hydraulic Concrete Test Procedure) [18], the compressive strength should be calculated as the arithmetic mean of the measured value of three specimens. Besides, in case that the difference between maximum or minimum compressive strength of one specimen and intermediate compressive strength of three specimens is $15 \%$ over the intermediate compressive strength, the intermediate compressive strength of these three specimens should be taken as the value of the compressive strength. The test will be invalid in the event of two specimens obeying the above provision, at this time, this experiment must be repeated. The relative compressive strength is defined as the ratio of concrete compressive strength under different drying conditions to that of under the standard condition. In this research, relative compressive strength was calculated on the basis of the experimental results, Fig. 2(a) and (b) show the curves of the relative compressive of concrete under different drying conditions. The relative splitting tensile strength can be 
obtained in a similar way, and Fig. 3(a) and (b) show the curves of the relative splitting tensile strength of concrete under different drying conditions.
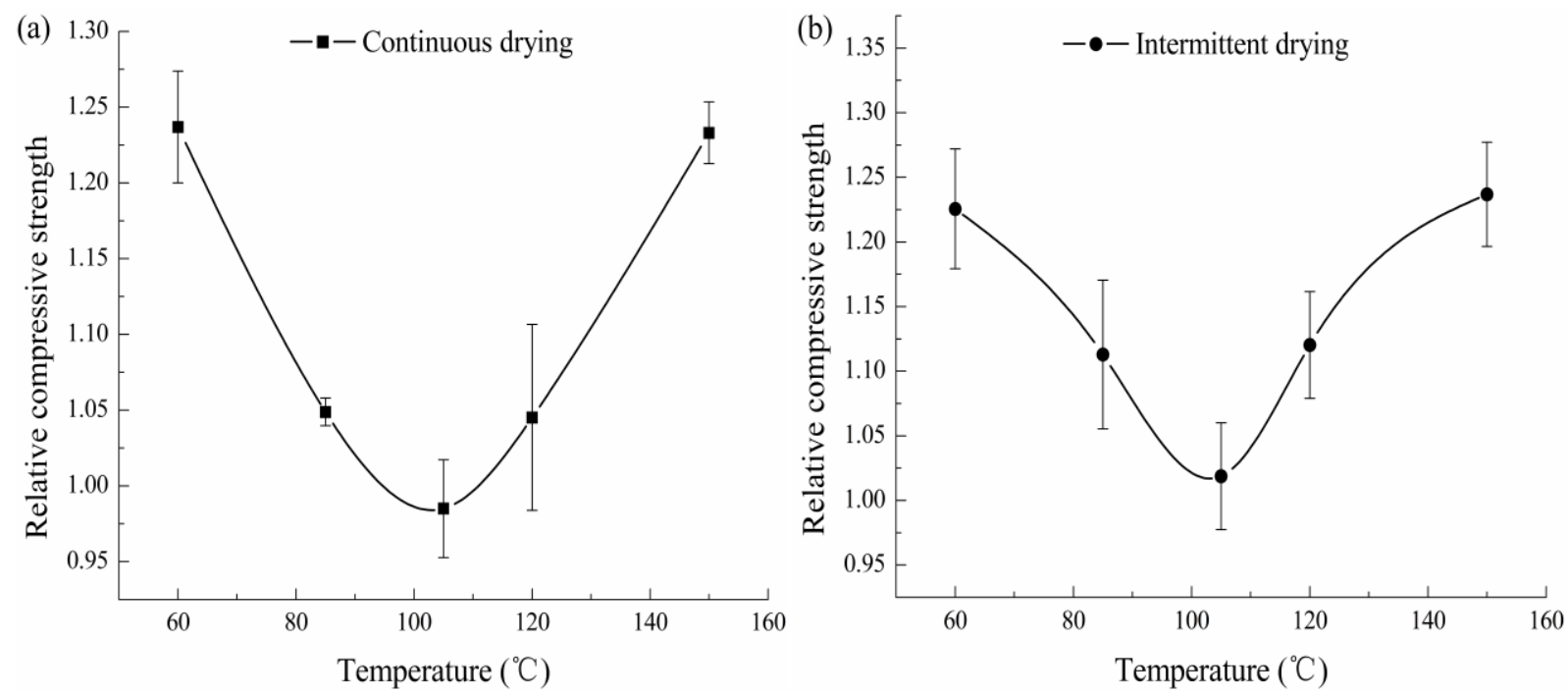

Fig. 2. Relative compressive strength of concrete specimens under continuous drying (a) and intermittent drying (b) (S.D. as error).
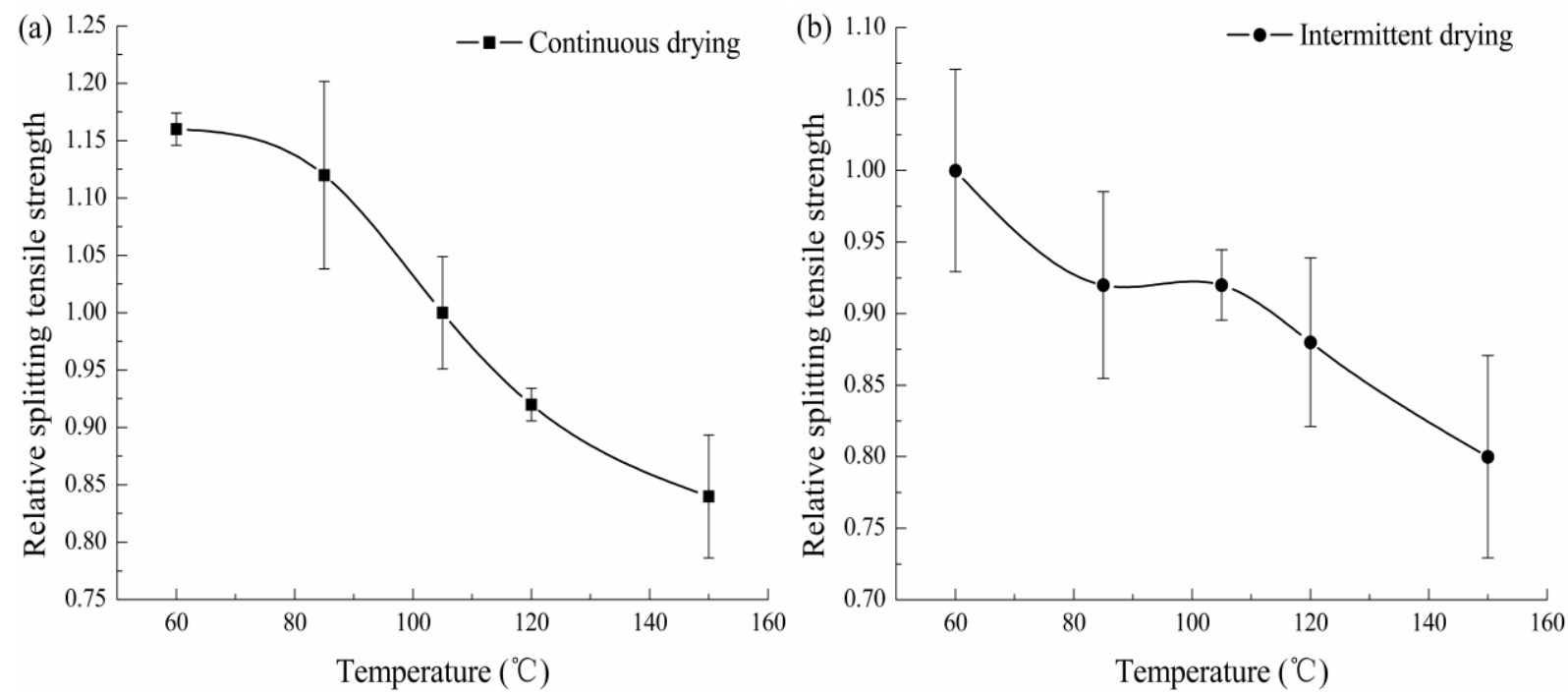

Fig. 3. Relative splitting tensile strength of concrete specimens under continuous drying (a) and intermittent drying (b) (S.D. as error).

As is shown in Fig. 2(a) and (b), initially the compressive strength of concrete specimens decreases with the increase in temperature but then increases during the continuous and intermittent drying cycle The compressive strength of concrete specimens after intermittent drying cycle is higher than that of continuous drying at the same 
drying temperature. In addition to the fourth group (i.e. continuous drying at $105{ }^{\circ} \mathrm{C}$ ), the compressive strength of concrete specimens is found higher than that of standard one. The compressive strength after continuous and intermittent drying cycle at $105{ }^{\circ} \mathrm{C}$ indicates a minimal value and found close to the standard compressive strength, with the relative compressive strength being observed as 0.99 and 1.02, respectively. The compressive strength after continuous drying at $60{ }^{\circ} \mathrm{C}$ and intermittent drying cycle at $150{ }^{\circ} \mathrm{C}$ indicates a maximum value, with the increase of nearly $24 \%$. In the view of minimal damage to the concrete compressive strength, both continuous and intermittent drying cycle at $105{ }^{\circ} \mathrm{C}$ can all ensure a minimal effect of the drying conditions on the compressive strength of the concrete specimens. Based on the experimental results, empirical equations are fitted for concrete compressive strength after continuous and intermittent drying cycle at different drying temperatures, as shown in Eqs. (1) and (2). The correlation coefficients are obtained as 0.98 and 0.99 , respectively.

$$
\begin{array}{ll}
\frac{f_{c}^{T}}{f_{c}}=1.314-0.332 e^{-7.019 \times 10^{-4}\left(T-1.04 \times 10^{2}\right)^{2}} & \left(60{ }^{\circ} \mathrm{C} \leqslant T \leqslant 150{ }^{\circ} \mathrm{C}, \text { Continuous drying }\right) \\
\frac{f_{c}^{T}}{f_{c}}=1.236-0.221 e^{-1.999 \times 10^{-3}\left(T-1.02 \times 10^{2}\right)^{2}} & \left(60{ }^{\circ} \mathrm{C} \leqslant T \leqslant 150{ }^{\circ} \mathrm{C}, \text { Intermittent drying }\right)
\end{array}
$$

Where $\mathrm{T}$ denotes the temperature $\left({ }^{\circ} \mathrm{C}\right) ; f_{c}^{T}$ represents the compressive strength of concrete measured under drying temperature $(\mathrm{MPa}) ; f_{c}$ represents the compressive strength of concrete measured at room temperature (MPa).

As is shown in Fig. 3(a) and (b), as compared to the compressive strength, the splitting tensile strength of concrete specimens does not show an decrease at first, but overall increases with the increase in drying temperature in a linear fashion. Only after continuous drying at $60{ }^{\circ} \mathrm{C}$ and $85{ }^{\circ} \mathrm{C}$, the splitting tensile strength of concrete specimens is found higher than the standard strength. After continuous drying at $60{ }^{\circ} \mathrm{C}$, the splitting tensile strength reaches the maximum value, and found larger than the standard splitting tensile strength by approximately $16 \%$. After intermittent drying cycle at $150{ }^{\circ} \mathrm{C}$, the splitting tensile strength of concrete specimens reaches the minimal value, and found $20 \%$ smaller than that of standard splitting tensile strength. After continuous drying at $105{ }^{\circ} \mathrm{C}$ 
and intermittent drying cycle at $60{ }^{\circ} \mathrm{C}$, the splitting tensile strength of concrete specimens is found consistent with the standard one. Only in view of the minimal damage to the concrete splitting tensile strength, both continuous drying at $105{ }^{\circ} \mathrm{C}$ and intermittent drying cycle at $60{ }^{\circ} \mathrm{C}$ can ensure a minimal effect of the drying conditions on the splitting tensile strength of concrete specimens. Based on the experimental results, empirical equations are fitted for concrete splitting tensile strength after continuous and intermittent drying cycle at different drying temperatures, as shown in Eqs. (3) and (4). The correlation coefficients in this case are obtained as 0.96 and 0.95 , respectively.

$$
\begin{array}{ll}
f_{t}^{T}=(1.407-0.004 T) f_{t} & \left(60{ }^{\circ} \mathrm{C} \leqslant T \leqslant 150{ }^{\circ} \mathrm{C}, \text { Continuous drying }\right) \\
f_{t}^{T}=(1.119-0.002 T) f_{t} \quad\left(60{ }^{\circ} \mathrm{C} \leqslant T \leqslant 150{ }^{\circ} \mathrm{C}, \text { Intermittent drying }\right)
\end{array}
$$

Where $f_{t}^{T}$ represents the splitting tensile strength of concrete measured under drying temperature (MPa); $f_{t}$ represents the splitting tensile strength of concrete measured at room temperature (MPa).

\section{Table 4}

\begin{tabular}{|c|c|c|c|c|c|c|}
\hline Test items & Factor & $\begin{array}{l}\text { Sum of } \\
\text { squares }\end{array}$ & $\begin{array}{l}\text { Mean } \\
\text { square }\end{array}$ & F Ratio & p-Value & $\begin{array}{l}\text { Significant } \\
\text { difference }\end{array}$ \\
\hline \multirow{3}{*}{$\begin{array}{l}\text { compressive } \\
\text { strength }\end{array}$} & $\begin{array}{l}\text { Continuous/ } \\
\text { Intermittent }\end{array}$ & 0.008 & 0.008 & 2.937 & 0.102 & No \\
\hline & Temperature & 0.254 & 0.063 & 23.105 & $2.927 \mathrm{E}-7$ & Yes \\
\hline & Interaction & 0.008 & 0.002 & 0.766 & 0.559 & No \\
\hline \multirow{3}{*}{$\begin{array}{l}\text { Splitting } \\
\text { tensile } \\
\text { strength }\end{array}$} & $\begin{array}{l}\text { Continuous/ } \\
\text { Intermittent }\end{array}$ & 0.081 & 0.081 & 17.634 & $4.413 \mathrm{E}-4$ & Yes \\
\hline & Temperature & 0.246 & 0.061 & 13.408 & $1.811 \mathrm{E}-5$ & Yes \\
\hline & Interaction & 0.031 & 0.08 & 1.721 & 0.184 & No \\
\hline
\end{tabular}

The double factor analysis of variance of continuous and intermittent drying with different drying temperature.

Table 4 present the double factor analysis of variance of continuous and intermittent drying with different drying temperature. The results in Table 4 show the drying procedure (continuous/ intermittent drying) has no obvious effect on the compressive strength while the temperature has significant influence. The drying procedure and dry temperature all have significant effect on splitting tensile strength. 


\section{Analysis of morphology and defects of concrete}

Based on the study of evolution rules of concrete compressive and splitting tensile strength under different drying conditions, the concrete after continuous drying at $105{ }^{\circ} \mathrm{C}$ exhibits nearly no damage as compared to the standard concrete compressive strength, and about $1 \%$ damage in case of splitting tensile strength. Thus, such drying control condition is deemed as nondestructive drying process for strength. In order to further study the evolution rules of the morphology and structure of the concrete after nondestructive drying, the phase compositions in the concrete are investigated by synchronously analyzing thermogravimetric differential thermal of the cement paste. In order to observe the changes in the morphology and structure of the concrete hydrates, the concretes collected before and after the nondestructive drying are scanned through the electron microscope. Finally, industrial CT three-dimensional scanning is used to quantitatively analyze the three-dimensional volume fraction of defect and its scale, and the distributions in concrete before and after the nondestructive drying.

\subsection{Analysis of phase compositions}

Thermogravimetric and differential thermal analyzer of model type TA-60WS+DTG-60A are used to conduct the thermogravimetric analysis of cement paste before and after the nondestructive drying. The test conditions are providing as heating rate of $10{ }^{\circ} \mathrm{C} / \mathrm{min}$, test temperature range between 25 to $600{ }^{\circ} \mathrm{C}$, and nitrogen as the gas medium. Three cement paste specimens are tested under the same experimental conditions, and the water cement ratio of cement paste is kept as same as that of concrete tested in Section 1.3. Drying temperature is taken as the abscissa, while the mass change of tested samples and the temperature difference with respect to the standard one are taken as the double ordinates. The analysis curves of the thermogravimetric and differential thermal analysis of cement paste are obtained as shown in Fig. 4. Thermogravimetric curve (TG) indicates that the mass change of cement paste occurred due to the temperature, while differential thermal analysis curve (DTA) indicates that the endothermic and exothermic phenomena resulted from the physical and chemical changes in cement paste occurred due to the increase in temperature. On the other hand, the quantitative analysis is conducted on the concrete 
hydrates by combining the physical and chemical characteristics during the heating process.

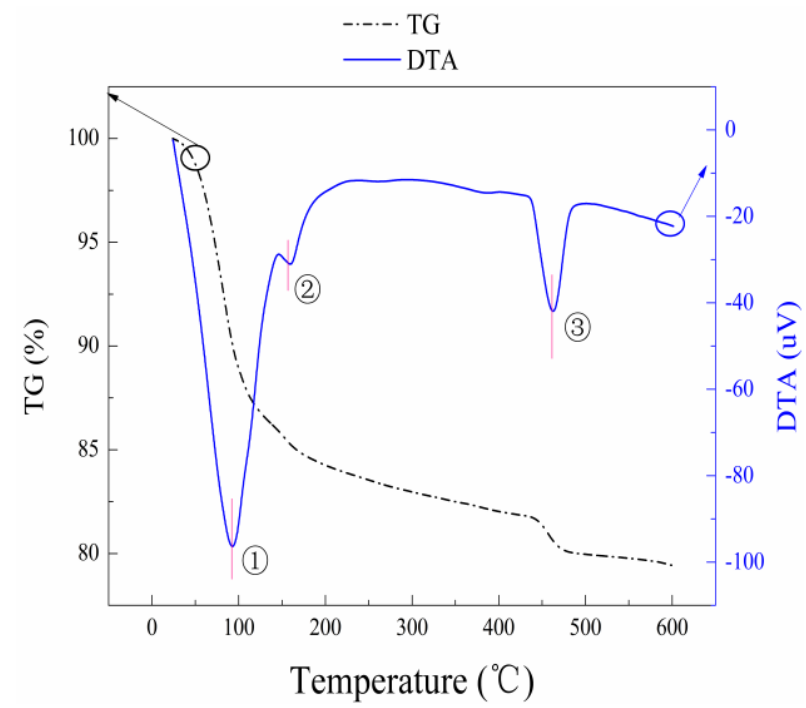

Fig.4. Thermo-Gravimetric and differential thermal analysis curve of cement paste(three replicates).

It can be seen in Fig. 4 that when the temperature is increases from $25{ }^{\circ} \mathrm{C}$ to $600{ }^{\circ} \mathrm{C}$, DTA curve shows three endothermic peaks, in which each one corresponds to one of the following physical and chemical reactions. (1) At the temperature change from $67{ }^{\circ} \mathrm{C}$ to $71{ }^{\circ} \mathrm{C}$, the evaporation loss of physical water occurs in the concrete, and the mass loss is about $21 \%$ of the total mass. (2) At the temperature change from $152{ }^{\circ} \mathrm{C}$ to $167{ }^{\circ} \mathrm{C}$, the concrete hydrates begin to dehydrate which leads to the tobermorites and ettringites decomposition in order that cause $3 \%$ loss in mass. (3) At the temperature from $373{ }^{\circ} \mathrm{C}$ to $520{ }^{\circ} \mathrm{C}$, calcium hydroxides in concrete hydrates begin to decompose, which is most significant at $471{ }^{\circ} \mathrm{C}$ and leads to a loss of $8 \%$ in mass. The above thermal analysis shows that the nondestructive drying condition of continuous drying at $105{ }^{\circ} \mathrm{C}$ is not responsible for the dehydration and decomposition of the hydrates in concrete, and in this case, only the physical free water contributes to the water loss. It is also explained that when the concrete reaches different drying states after the action of different drying temperature, both water loss and measured moisture content increases with the increase in drying temperature. For example, after continuous drying at $150{ }^{\circ} \mathrm{C}$, except physical water loss occurred due to the 
evaporation, tobermorites and ettringites dehydrate in order and the measured moisture content includes both the free and bound water content. In this case, the loss of water mass and measured moisture content are obtained as 1.17 and 1.21 times, respectively, that of nondestructive drying conditions.

\subsection{Analysis of morphology}

The concretes before and after the nondestructive drying are scanned by using the Tungsten Filament Scanning Electron Microscope of type JSM-6360LV. Acceleration voltage is kept at $30 \mathrm{kV}$ with magnification factor of 1000 times. The test samples are blocky-shaped particles extracted from the concrete cube specimens, and the dimension is smaller than $1 \mathrm{~cm}$ with regular shape and smooth surface. Three samples after the nondestructive drying and three normal samples are tested. The two classic images are reported in this research on account of space limitation, Fig. 5 shows the scanned picture of morphology of concrete hydrates under the standard conditions, while Fig. 6 represents the specimens with nondestructive drying.

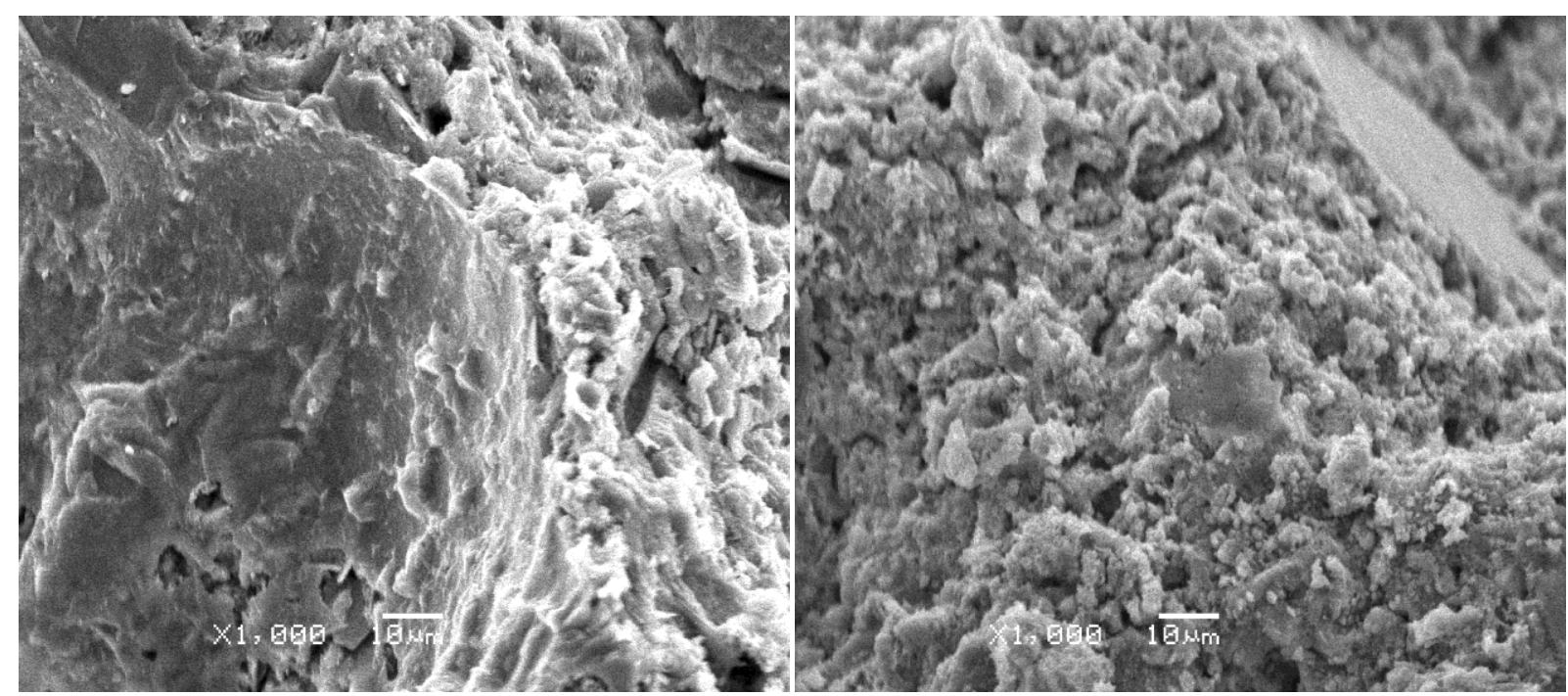

Fig. 5. Microstructure of cement-hydrate at normal state.

Fig. 6. Microstructure of cement-hydrate after $105^{\circ} \mathrm{C}$ continuous drying.

It is evident from the Figs. 5 and 6 that continuous drying at $105{ }^{\circ} \mathrm{C}$ promotes the continuous process of hydration reactions in the concrete, which increases the amount of internal hydrates. Besides, the organization structure is found denser and intact with less microcosmic pores than that of normal states, which is beneficial for 
increasing the concrete strength. When the drying temperature increases to $150{ }^{\circ} \mathrm{C}$, chemical bound water begins to evaporate and the molecular structure of hydrates begins to change with it. The main hydration product of the cement mortar in the transition zone is C-S-H, whose volume percentage is about $60-70 \%$ and whose strength directly dictate the macroscopic mechanical properties of concrete. The molecular structure diagrams of C-S-H at normal state and dry state were given [19], and the mechanism relation to the effect of elevated temperature on the mechanical properties of concrete was interpreted from the perspective of molecular dynamics, as shown in Fig. 7(a) and (b).
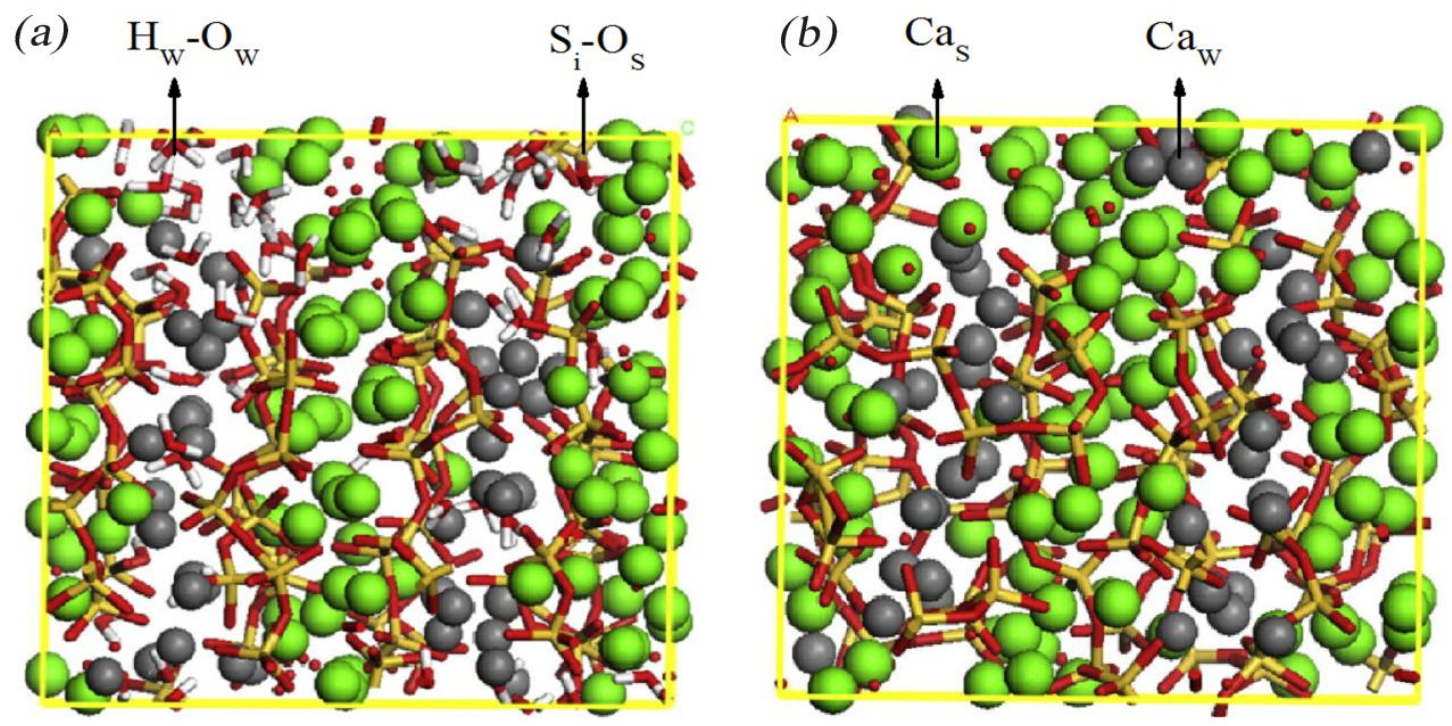

Fig. 7. Snapshots of the molecular structures of C-S-H gel samples under normal state (a) and dry state (b).

Note: The figure is quoted from literature [19], red chains and yellow for $\mathrm{Si}_{-} \mathrm{O}_{\mathrm{S}}$, grey for interlayer $\mathrm{Ca}_{\mathrm{w}}$ atom $\mathrm{O}_{\mathrm{W}}$, green for $\mathrm{Ca}$ atom $\mathrm{Ca}_{\mathrm{S}}$, and white chains and red for water molecules.

The molecular structure of C-S-H is one layer of calcium oxygen laminar structure sandwiched between two layers of silicon oxygen tetrahedron chain [20]. In normal state as shown in Fig. 7(a), Most water molecules exist in the interlayer zones of $\mathrm{C}-\mathrm{S}-\mathrm{H}$, and a small number of water molecules are dispersed in the silicon oxygen tetrahedron chain and calcium oxygen laminar zones. The interlayer zone in the whole molecular system is evident [21]. The mobility of interlayer water molecules is temperature-dependent, and water content decrease until reach a 
dry state for the self-diffusivity of water molecules increases with the elevation of temperature. The $\mathrm{Ca}$ and $\mathrm{Si}$ atoms in $\mathrm{C}-\mathrm{S}-\mathrm{H}$ molecule are superposed partially, the interlayer zones are reduced, the whole molecular structure system becomes compact, the atoms are arranged closely with evident disordering, as shown in Fig. 7(b). The oxygen atoms $\mathrm{O}_{\mathrm{W}}$ in water molecules to form $\mathrm{Ca}_{\mathrm{W}}-\mathrm{O}_{\mathrm{W}}$ and $\mathrm{Ca}_{\mathrm{S}}-\mathrm{O}_{\mathrm{W}}$ is partially replaced by $\mathrm{O}_{\mathrm{S}}$ (oxygen atom in C-S-H molecule) in $\mathrm{Ca}_{\mathrm{W}}-\mathrm{O}_{\mathrm{S}}$ and $\mathrm{Ca}_{\mathrm{S}}-\mathrm{O}_{\mathrm{S}}$. Because $\mathrm{Ca}_{\mathrm{W}}-\mathrm{O}_{\mathrm{S}}, \mathrm{Ca}_{\mathrm{S}}-\mathrm{O}_{\mathrm{S}}$, and $\mathrm{O}_{\mathrm{S}}-\mathrm{H}_{\mathrm{W}}$ have smaller bond lengths than $\mathrm{Ca}_{\mathrm{W}}-\mathrm{O}_{\mathrm{w}}, \mathrm{Ca}_{\mathrm{S}}-\mathrm{O}_{\mathrm{w}}$, and $\mathrm{O}_{\mathrm{W}}-\mathrm{H}_{\mathrm{W}}$, so these chemical bonds have decrease in length, but increase in strength, the stability of whole molecular system improves[19]. it's worth noting that intragranular cohesion increased monotonically with increasing temperature within $192{ }^{\circ} \mathrm{C}$, and then the cohesive strength are weakened due to the breakage of silicate chains and reduced stability of the chemical bonds, when the temperature is beyond $192{ }^{\circ} \mathrm{C}$ $[23,24]$. The range of temperature in this research is no more than $192{ }^{\circ} \mathrm{C}$, the cohesive strength of C-S-H molecule monotonically increase at elevated temperature.

\subsection{Analysis of defects structure}

The more representative geometrical model can be obtained directly from the real structure of the materials based on the image from X-ray. XCT technology is characterized by high resolution nondestructive test and clear three-dimensional interior view, and has been applied in many studies for deducing the interior geometrical characteristics of the concrete [25-27]. In this paper, XCT is used to conduct the 3D scanning of concrete before and after the nondestructive drying. The voltage and current of the $\mathrm{X}$-ray tube are $210 \mathrm{kV}$ and $0.63 \mathrm{~mA}$, respectively. The detector type is flat panel Y.XRD1620, and the numbers of detector elements are 1024. The numbers of projections are 1080 . The $2 \mathrm{D}$ pixel size are $0.13 \mathrm{~mm} \times 0.13 \mathrm{~mm}$, pixel numbers are $1024 \times 1024$. The $3 \mathrm{D}$ voxel size are $0.13 \mathrm{~m} \times 0.13 \mathrm{~mm} \times 0.13 \mathrm{~mm}$. The object rotation angles are $360^{\circ}$. Through the three-dimensional reconstruction of concrete specimens by the XCT bundled software VG Studio MAX 2.2, and by extracting the interior deflects in concrete by the bundled deflect analysis module, the three-dimensional defects in 
concrete specimens under standard state and after nondestructive drying conditions are obtained, respectively.

Specimens are cylindrical in shape with a dimension of $\Phi 100 \mathrm{~mm} \times 100 \mathrm{~mm}$ extracted from the concrete cube specimens. Three normal samples are scanned respectively, and These cylindrical specimens are scanned again after nondestructive drying respectively. The results are calculated as the arithmetic mean of the measured value of three specimens. Quantity and volume fraction of defects in concrete specimens after 28 days of standard curing and after continuous nondestructive drying at $105{ }^{\circ} \mathrm{C}$ are summarized in Table 5 . It is evident from Table 5 that the number and volume fraction of defects in concrete after nondestructive drying are greater than that of standard condition. It is further observed that the volume fraction of defects is increased by $20 \%$ respect to the standard concrete, while the number of defects increases by $42 \%$ as compared to standard. Further, the defects has diameter ranges from 0.32 to $13.58 \mathrm{~mm}$, which is harmful to the strength. Moreover, the increase in the porosity has a deteriorating effect on the concrete strength. In order to analyze the effect laws of nondestructive drying condition on the distribution of defects volume, the change in the quantity of defects in different dimensions before and after the nondestructive drying are counted. The distributions of the quantity of defects with different volumes are summarized in Table 6, while that of different diameters are summarized in Table 7.

\section{Table 5}

Defect changes due to $105{ }^{\circ} \mathrm{C}$ continuous drying.

\begin{tabular}{lllllll}
\hline \multirow{2}{*}{ Conditions } & $\begin{array}{l}\text { Defect } \\
\text { volume } \\
\left(\mathrm{mm}^{3}\right)\end{array}$ & $\begin{array}{l}\text { Total volume } \\
\left(\mathrm{mm}^{3}\right)\end{array}$ & $\begin{array}{l}\text { Defect volume } \\
\text { fractions }(\%)\end{array}$ & $\begin{array}{l}\text { Numbers } \\
\text { of defects }\end{array}$ & $\begin{array}{l}\text { Maximum } \\
\text { diameter } \\
(\mathrm{mm})\end{array}$ & $\begin{array}{l}\text { Minimum } \\
\text { diameter }(\mathrm{mm})\end{array}$ \\
\hline Normal & 4385 & 508938 & 0.9 & 4858 & 13.54 & 0.32 \\
Dry & 5255 & 508938 & 1.1 & 6879 & 13.58 & 0.32 \\
\hline
\end{tabular}

Table 6

Defect volume distribution changes due to $105{ }^{\circ} \mathrm{C}$ continuous drying .

\begin{tabular}{|c|c|c|c|c|c|c|}
\hline \multirow{2}{*}{ Range of volume $\left(\mathrm{mm}^{3}\right)$} & \multicolumn{3}{|c|}{ Numbers of defects } & \multicolumn{3}{|c|}{ Proportion of defects $(\%)$} \\
\hline & Normal & Dry & Difference & Normal & Dry & Difference \\
\hline $0.02-0.2$ & 2998 & 4831 & 1833 & 65.4 & 70.2 & 4.8 \\
\hline
\end{tabular}




\begin{tabular}{|c|c|c|c|c|c|c|}
\hline $0.2-0.3$ & 419 & 493 & 74 & 9.1 & 7.2 & -1.9 \\
\hline $0.3-0.4$ & 229 & 325 & 96 & 5 & 4.7 & -0.3 \\
\hline $0.4-0.5$ & 134 & 205 & 71 & 2.9 & 3 & 0.1 \\
\hline $0.5-0.7$ & 200 & 258 & 58 & 4.4 & 3.8 & -0.6 \\
\hline $0.7-1$ & 148 & 198 & 50 & 3.2 & 2.9 & -0.4 \\
\hline $1-2$ & 203 & 270 & 67 & 4.4 & 3.9 & -0.5 \\
\hline $2-4$ & 116 & 141 & 25 & 2.5 & 2.1 & -0.5 \\
\hline $4-10$ & 62 & 73 & 11 & 1.4 & 1.1 & -0.3 \\
\hline $10-20$ & 38 & 40 & 2 & 0.8 & 0.6 & -0.3 \\
\hline $20-200$ & 38 & 45 & 7 & 0.8 & 0.7 & -0.2 \\
\hline
\end{tabular}

\section{Table 7}

Defect diameter distribution changes due to $105{ }^{\circ} \mathrm{C}$ continuous drying.

\begin{tabular}{|c|c|c|c|c|c|c|}
\hline \multirow{2}{*}{ Range of diameter (mm) } & \multicolumn{3}{|c|}{ Numbers of defects } & \multicolumn{3}{|c|}{ Proportion of defects $(\%)$} \\
\hline & Normal & Dry & Difference & Normal & Dry & Difference \\
\hline $0.32-1$ & 3211 & 4859 & 1648 & 70.1 & 70.8 & 0.7 \\
\hline $1-1.2$ & 481 & 690 & 209 & 10.5 & 10.1 & -0.5 \\
\hline $1.2-1.4$ & 264 & 403 & 139 & 5.8 & 5.9 & 0.1 \\
\hline $1.4-1.7$ & 241 & 247 & 6 & 5.3 & 3.6 & -1.7 \\
\hline $1.7-2$ & 123 & 280 & 157 & 2.7 & 4.1 & 1.4 \\
\hline $2-5$ & 217 & 333 & 116 & 4.7 & 4.9 & 0.1 \\
\hline $5-15$ & 41 & 50 & 9 & 0.9 & 0.7 & -0.2 \\
\hline
\end{tabular}

As shown in Table 6, the quantity of interior defects with a volume between $0.02 \mathrm{~mm}^{3}$ and $0.2 \mathrm{~mm}^{3}$ before and after the nondestructive drying conditions contributes to the most of the total quantity, and the proportions are $65 \%$ and $70 \%$ respectively. Besides, with the increase in defect volumes, a decrease is observed in the proportion of the quantity of defects. For example, the proportions of defects with a volume between $20 \mathrm{~mm}^{3}$ and $200 \mathrm{~mm}^{3}$ are only about $0.9 \%$ and $0.7 \%$, respectively. After nondestructive drying, the increase in the quantity of defects with a volume between $0.32 \mathrm{~mm}^{3}$ and $0.2 \mathrm{~mm}^{3}$ is significant and the quantity is 1.6 times that of standard condition. The quantity of defects with a volume between $0.4 \mathrm{~mm}^{3}$ and $0.5 \mathrm{~mm}^{3}$ is 1.5 times that of standard condition. However, the increase in the quantity of defects with the large volumes is lower than that of small volumes. For example, the increase in the quantity of defects with a volume between $10 \mathrm{~mm}^{3}$ and $20 \mathrm{~mm}^{3}$ is only about $5.3 \%$.

As shown in Table 7, the quantity of interior defects with a diameter between $0.32 \mathrm{~mm}$ and $1.0 \mathrm{~mm}$ before and 
after nondestructive drying contributes the most to the total quantity, and the proportions all are $70 \%$, With the increase in defect diameter, the proportion of the quantity decreases. For example, the proportions of defects with a diameter between $5 \mathrm{~mm}$ and $15 \mathrm{~mm}$ are only $0.9 \%$ and $0.7 \%$, respectively. After the continuous drying at $105^{\circ} \mathrm{C}$, the increase in the quantity of defects with a diameter between $0.32 \mathrm{~mm}-1 \mathrm{~mm}$ and $1.7 \mathrm{~mm}-2 \mathrm{~mm}$ are the most significant, the quantity of defects with a diameter between $0.32 \mathrm{~mm}-1 \mathrm{~mm}$ is obtained as 1.5 times higher that of standard condition. and the quantity of defects with a diameter between $1.7 \mathrm{~mm}-2 \mathrm{~mm}$ is about 2.3 times higher that of standard condition. The increase in the quantity of defects with other diameters ranges are approximatively similar.

\section{Discussions}

The evolution laws of concrete strength under different drying conditions are further explained. With the increase in drying temperature, the hydration reactions in concrete are strengthened. The organization structure of hydrates is found denser and more intact than that of standard condition, which is beneficial for increasing the concrete strength. Meanwhile, three-dimensional CT scans of concrete before and after the drying at $105^{\circ} \mathrm{C}$ shows that there is an increase in the quantity of interior defects of concrete after the nondestructive drying. The volume fraction of defects increases by $20 \%$ as compared to the standard concrete, and the number of defects increases by $42 \%$ cause a deteriorating effect on the strength. Since such deterioration effect does not totally compensate the strengthening effect of increasing temperature on compressive strength, the concrete compressive strength decreases after the continuous and intermittent drying cycle at the drying temperature between $60{ }^{\circ} \mathrm{C}$ and $105{ }^{\circ} \mathrm{C}$. Beside, the growth effect of the compressive strength compensates exactly the deteriorating effects at the continuous drying at $105{ }^{\circ} \mathrm{C}$. At this point, the compressive strength is nearly identical to that of standard condition. There is a continuous increase in the quantity of hydrates with temperature further increases from $120{ }^{\circ} \mathrm{C}$ to $150{ }^{\circ} \mathrm{C}$, and chemical bonds of C-S-H molecule have decrease in length, increase in strength, the stability of whole 
molecular system improves. This induces the recovery of concrete compressive strength at temperatures between $105{ }^{\circ} \mathrm{C}$ and $150{ }^{\circ} \mathrm{C}$. The mechanism of influence of drying conditions on the concrete splitting tensile strength is similar to that of compressive strength. However, concrete splitting tensile strength is more sensitive to defects than the compressive strength, there exists a difference between the change laws. The deterioration effect of splitting tensile strength is more significant than that of strengthening effect. So the splitting tensile strength of the concrete shows a linear decrease at the temperature between $60{ }^{\circ} \mathrm{C}$ and $150{ }^{\circ} \mathrm{C}$.

The concrete natural porosity decreases with the decrease in water/cement of concrete, so the internal structure of high-strength-concrete (HSC) is denser than low-strength-concrete (LSC). The solid moisture in concrete is transferred to water vapor at elevated temperature, and water vapour is difficult to diffuse outside due to natural low porosity of HSC. The constantly diffusion of water vapour with the increase of temperature may cause new cracks in HSC, and these new cracks may result in the decrease of strength of HSC [28]. The strength loss of HSC is greater than the LSC at same elevated temperature, the strength of HSC have higher sensitivity to elevated temperatures. Concrete will produce tensile stress due to effect of water vapour diffusion and concrete solid dry shrinkage at elevated temperature, and new cracks will be caused when the tensile stress exceeds limit value. The concrete with a short curing age can well adapt to its volume change with the increase of temperature. In other words, the elevated temperature condition cause more new cracks in long curing age concrete than short curing age concrete. The strength loss of long curing age is greater than the short curing age at same elevated temperature $[29,30]$. it's worth noting that the role of elevated temperature on the strength of concrete is complicated. In order to get the optimal drying control condition has minimal effect on the strength of concrete with different water/cement ratios and curing ages, an experimental investigation will be completed in future studies.

\section{Conclusions}

The compressive strength of the concrete specimens are initially increases and then decreases with the 
temperature after continuous and intermittent drying cycle and $105{ }^{\circ} \mathrm{C}$ is found as the turning point. At the same drying temperature, the compressive strength of the concrete specimens after intermittent drying cycle is higher than that of continuous drying. The splitting tensile strength of the concrete specimens is showing an overall decrease in a linear fashion with the drying temperature after continuous and intermittent drying cycle. The dried concrete relative compressive and splitting tensile strengths are obtained as 1 and 0.99 respectively after $115.5 \mathrm{~h}$ of continuous drying at $105{ }^{\circ} \mathrm{C}$. This indicates that the drying control condition is the optimal one with nearly no effect on the strength.

\section{Acknowledgments}

The authors gratefully acknowledge the financial support of National Science Foundation of China (Grant No. 51379178).

\section{References:}

[1] E. Cadoni, K. Labibes, C. Albertini, M. Berra, M. Giangrasso, Strain-rate effect on the tensile behavior of concrete at different relative humidity levels, Mater. Struct. 34(1) (2001) 21-26.

[2] F.M. Bartlett, J.G. Macgregor, Effect of moisture condition on concrete core strengths, ACI Mater. J. 91(3) (1994) 227-236.

[3] P. Rossi, Influence of cracking in presence of free water on the mechanical behavior of concrete, Mag. Concrete Res. 43(154) (1991) 53-57.

[4] P. Rossi, C. Boulay, Influence of free water in concrete on the cracking process, Mag. Concrete Res. 42(152) (1990) 143-146.

[5] C.A. Ross, D.M. Jerome, J.W. Tedesco, M.L. Hughes, Moisture and strain rate effects on concrete strength, ACI Mater. J. 93(3) (1996) 293-300.

[6] G.H. Zhang, Z.L. Li, K.Y. Nie, M.H. Liu, Experimental study on fracture toughness of concrete with different 
moisture contents, J. Hydr. Eng. 35(2) (2016) 109-116.

[7] H. Wang, L.C. Wang, Y.P. Song, J.Z. Wang, Influence of free water on dynamic behavior of dam concrete under biaxial compression, Constr. Build. Mater. 112 (2016) 222-231.

[8] H.L. Wang, Q.B. Li, Experiments of the compressive properties of dry and saturated concrete under different loading rates, J. Hydr. Eng. 26(1) (2007) 84-89.

[9] H.L. Wang, Q.B. Li, Experiments on saturated concrete under different splitting tensile rate and mechanism on strength change, Eng. Mech. 24(2) (2007) 105-109.

[10] B.D. Liu, W.J. Lv, L. Li, P.F. Li, Effect of moisture content on static compressive elasticity modulus of concrete, Constr. Build. Mater. 69(11) (2014) 133-142.

[11] J.K. Zhou, N. Ding, Moisture effect on compressive behavior of concrete under dynamic loading, J. Cent. South Univ. 21(12) (2014) 4714-4722.

[12] J.K. Zhou, X.D. Chen, L.Q. Wu, X.W. Kan, Influence of free water content on the compressive mechanical behaviour of cement mortar under high strain rate, Sādhanā. 36(3) (2011) 357-369.

[13] J.C.P.H. Gamage, R. Al-Mahaidi, M.B. Wong, Integrity of CFRP-concrete bond subjected to long-term cyclic temperature and mechanical stress, Compos. Struct. 149 (2016) 423-433.

[14] A. Pineaud, P. Pimienta, S. Rémond, H. Carré, Mechanical properties of high performance self-compacting concretes at room and high temperature, Constr. Build. Mater., 112 (2016) 747-755.

[15] R. Felicetti, P.G. Gambarova, Effects of high temperature on the residual compressive strength of high-strength siliceous concretes, ACI Mater. J. 95(4) (1998) 395-405.

[16] C.J. Zega, A.A. Di-Maio, Recycled concrete made with different natural coarse aggregates exposed to high temperature, Constr. Build. Mater. 23(5) (2009 )2047-2052.

[17] W.A. Al-Khaja, Influence of temperature, cement type and level of concrete consolidation on chloride ingress 
in conventional and high-strength concretes, Constr. Build. Mater. 11(1) (1997) 9-13.

[18] The people's republic of China industry standard SL 352-2006, Test Code for Hydraulic Concrete.

[19] D.S. Hou, H.Y. Ma, Z. Yu, Z.J. Li, Calcium silicate hydrate from dry to saturated state: structure dynamics and mechanical properties, Acta. Mater. 67 (2014) 81-94.

[20] H.M. Jennings, A model for the microstructure of calcium silicate hydrate in cement paste, Cem. Concr. Res. 30(1) (2000) 101-116.

[21] P.A. Bonnaud, Q. Ji, B. Coasne, R.J.M. Pellenq, K.J. Van Vliet, Thermodynamics of water confined in porous calcium-silicate-hydrates, Langmuir. 28(31) (2012) 11422-11432.

[22] D.S. Hou, T.J. Zhao, H.Y. Ma, Z.J. Li, Reactive molecular simulation on water confined in the nanopores of the calcium silicate hydrate gel: structure, reactivity, and mechanical properties, J. Phys. Chem. C. 119(3) (2015) 1346-1358.

[23] P.A. Bonnaud, Q. Ji, K.J. Van Vliet, Effects of elevated temperature on the structure and properties of calcium-silicate-hydrate gels: the role of confined water, Soft Matter. 9(28) (2013) 6418-6429.

[24] D.S. Hou, D.K. Li, T.J. Zhao, Z.J. Li, Confined water dissociation in disordered silicates nanometer-channels at elevated temperatures: mechanism, dynamics and impact on the substrates, Langmuir. 32(17) (2016) 4153-4168.

[25] P.S. Le, E. Fratini, K. Ito, Z. Wang, et al., Dynamical behaviors of structural, constrained and free water in calcium- and magnesium-silicate-hydrate gels, J. Colloid Interf. Sci. 469 (2016) 157-163.

[26] T. Rougelot, N. Burlion, D. Bernard, F. Skoczylas, About microcracking due to leaching in cementitious composites: X-ray microtomography description and numerical approach, Cem. Concr. Res. 40(2) (2010) 271-283.

[27] E. Gallucci, K. Scrivener, A. Groso, M. Stampanoni, G. Margaritondo, 3D experimental investigation of the microstructure of cement pastes using synchrotron X-ray microtomography $(\mu \mathrm{CT})$, Cem. Concr. Res. 37(3) (2007) 360-368. 
[28] U. Schneider, Concrete at high temperatures — A general review, Fire Safety J. 13(1) (1988) 55-68.

[29] H. Tanyildizi, Y. Yonar, Mechanical properties of geopolymer concrete containing polyvinyl alcohol fiber exposed to high temperature, Constr. Build. Mater. 126 (2016) 381-387.

[30] C.S. Pillai, A.R. Santhakumar, A. Poonguzhali, et al., Evaluation of microstructural and microchemical aspects of high density concrete exposed to sustained elevated temperature, Constr. Build. Mater. 126 (2016) 453-465. 


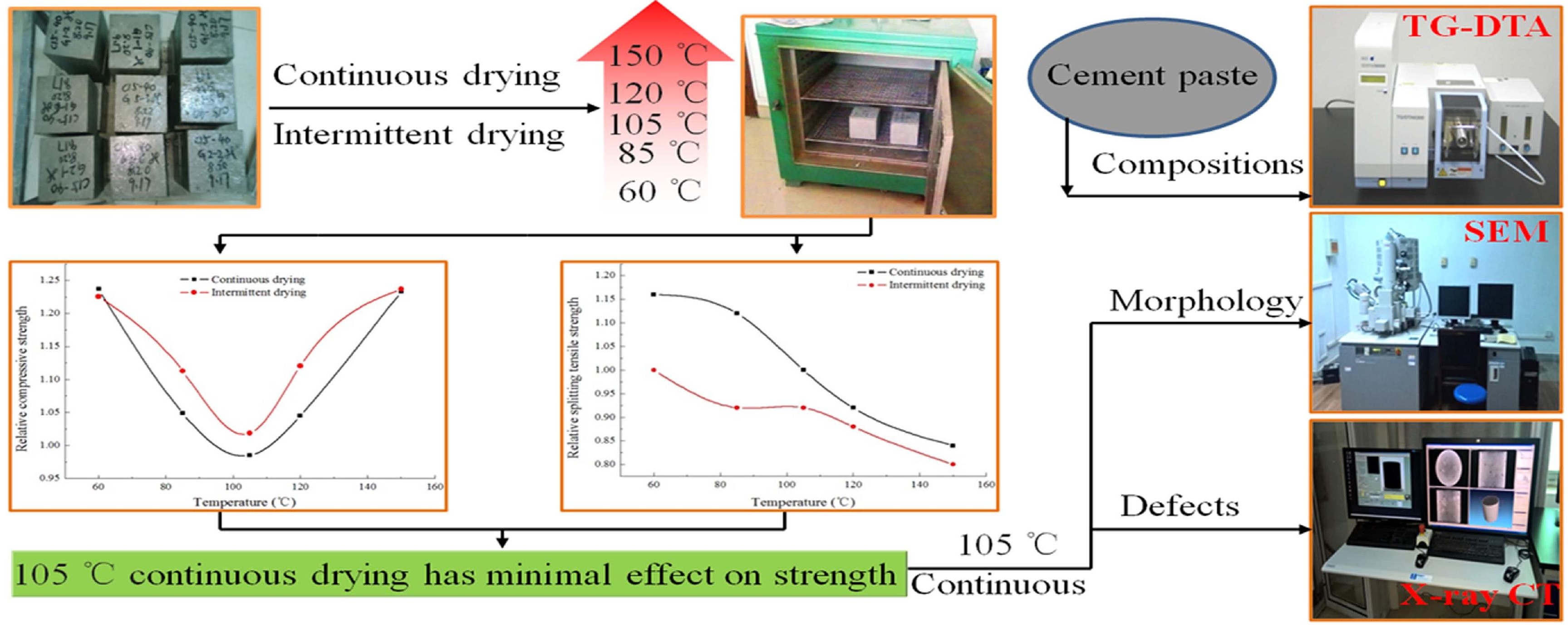

